\title{
SATELLITE MAPPING OF GORSE AT REGIONAL SCALES
}

\author{
J.D. SHEPHERD ${ }^{1}$ and W.G. LEE ${ }^{2}$
}

\author{
${ }^{1}$ Landcare Research, Private Bag 11052, Palmerston North \\ ${ }^{2}$ Landcare Research, Private Bag 1930, Dunedin \\ Corresponding author: shepherdj@landcare.cri.nz
}

\begin{abstract}
The spatial distribution of gorse in the Wellington Region was mapped using Landsat satellite imagery. This satellite is capable of mapping at regional scales (1:50 000), with a large spatial extent $(180 \mathrm{~km} \times 180 \mathrm{~km})$, and has spectral bands in both the visible and infrared parts of the spectrum ( 6 bands in total). A spring Landsat image distinguished flowering gorse, enabling mapping of gorse as a separate scrub type. We chose a minimum patch size of 0.5 ha with a boundary precision of $\pm 15 \mathrm{~m}$. An error assessment using 1200 stratified random samples across the Wellington region compared the satellite classified result with colour aerial orthophotography and found the mapping accuracy of gorse to be $95 \%$. Gorse area by catchment was calculated using an existing GIS of catchment boundaries. The area and percent cover of gorse within a catchment is a potential way to target management at regional scales.

Keywords: Ulex europaeus, monitoring, scrub weeds, satellite.
\end{abstract}

\section{INTRODUCTION}

Gorse (Ulex europaeus) is a widespread scrub weed with both economic and environmental impacts. Assessing its impact at regional scales is difficult, as it is costly to adequately sample large areas at sufficient detail. Remote sensing can play a useful role in measuring spatial extent of weed coverage, and by recording images in different years, can also determine rates of spread. In most instances the best opportunity for scrub weed discrimination occurs during flowering periods. Gorse flowers twice a year, with the heaviest flowering in spring. Its yellow flowers are dominant at this time, enabling separation from other narrow leaf scrub types such as manuka (Leptospermum scoparium) and kanuka (Kunzea ericoides). The imagery for this gorse study was from the Landsat 7 satellite, which was chosen primarily for its spatial extent, as only one image was needed to map the entire Wellington region. It has the normal visible bands, blue, green and red, so flowering can be seen as yellowing, but it also has spectral bands in infrared parts of the spectrum that improve general vegetation discrimination. The image was acquired on 30 September 1999 during the spring flowering period.

\section{METHODS}

Landsat 7 imagery comes in two forms: a 30 m resolution 6-band multispectral (colour) image and a $15 \mathrm{~m}$ resolution panchromatic (black and white) image. The $30 \mathrm{~m}$ resolution of the colour imagery is not quite detailed enough for 1:50 000 scale mapping, but Landcare Research has developed a "Pan-Sharpening" algorithm which takes advantage of the high spatial resolution of the black and white image to resample the colour imagery to $15 \mathrm{~m}$ pixel detail (Dymond et al. 2001). The next step in the image processing is to orthorectify the sharpened imagery to the New Zealand map grid. This is achieved using mapping software with a network of ground control points extracted from LINZ 1:25 000 orthophotos. The mapping error of this method is $20 \mathrm{~m}$. The third and most difficult step of the process is to remove the effect of topography within the image. The varying slope and aspect of land surfaces affect both the amount of incoming light and the proportion 
of light reflected from these surfaces (Dymond \& Shepherd 1999). For a computer to classify vegetation accurately in rugged terrain, colour variations due to topography must be removed so that the observed colour corresponds to vegetation type alone. Topographic correction requires knowledge of the slope and aspect of each pixel, which was calculated from a $15 \mathrm{~m}$ Digital Elevation Model built from NZMS $26020 \mathrm{~m}$ contours. The topographic correction method used was that of Shepherd \& Dymond (In press).

Classification of the gorse first involved manually highlighting a few test areas that corresponded with closed canopy gorse in flower. These areas were used to produce a spectral signature for flowering gorse, and from this pure signature a colour distance between the test data and every image pixel was calculated. Defining thresholds for spectral distance values then gave a method to classify gorse. Unfortunately, setting the threshold large enough to capture all the flowering gorse incorporated significant amounts of non-target vegetation, so an iterative method was required.

This method involved first using a tight spectral distance to highlight pure gorse areas. These areas were manually checked to ensure no false starting points. From the pure areas a connected buffer zone was calculated and the spectral distance threshold was relaxed slightly within this zone. After several iterations of buffering and increasing the threshold, diminishing gorse classified pixels indicated convergence. This iterative classification method assumed any gorse-like pixels in the proximity of a pure closed canopy source were indeed gorse. Finally, a clumping analysis was performed and only connected clumps greater than 0.5 ha were retained. This connectivity gave more confidence to the classified result, removing any instances of isolated mixed pixels matching the threshold criteria.

\section{RESULTS}

The extent of gorse in the Wellington region is shown in Figure 1. The area of mapped gorse was $4767 \mathrm{ha}$, which is $0.56 \%$ of the land area of the region. The accuracy of the classification was calculated by manual comparison of the gorse map with $1 \mathrm{~m}$ colour ortho-photography. This error assessment involved 1200 stratified random samples. Results are given in Table 1, from which we calculated the proportion of mapped gorse pixels that were actually gorse to be $95 \%$. The proportion of actual gorse pixels that were mapped as gorse was $97 \%$.

TABLE 1: Contingency table showing proportions of pixels falling in mapped classes and actual classes.

\begin{tabular}{lcccc}
\hline & & \multicolumn{2}{c}{ Actual class } & \\
\cline { 2 - 4 } & & gorse & other & \\
\hline $\begin{array}{llcll}\text { Satellite } \\
\text { mapped } \\
\text { class }\end{array}$ & gorse & 0.0056 & 0.0003 & 0.0059 \\
\cline { 2 - 4 } & other & 0.0002 & 0.9939 & 0.9941 \\
\hline & & 0.0058 & 0.9942 & \\
\hline
\end{tabular}

\section{DISCUSSION}

Satellite imagery provides an accurate and practical approach to assessing the extent of gorse at a regional scale. However, the spatial pattern of gorse throughout the region is also produced by satellite mapping. Management of gorse as either a threat to agriculture or as a nurse crop for indigenous biodiversity, might require more detailed statistics, such as a summary of gorse distribution by catchment or within a particular climatic zone. Table 2 gives an example of gorse statistics by catchment. 

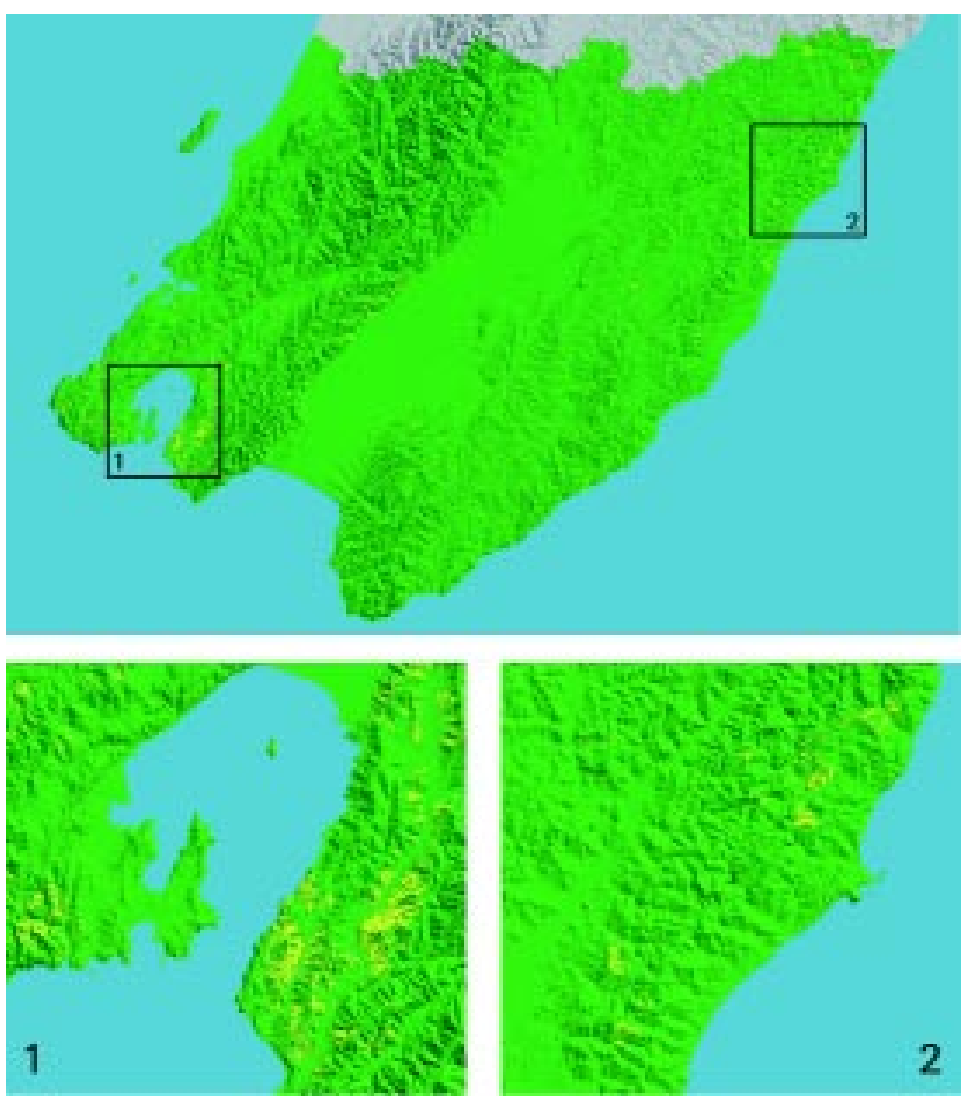

FIGURE 1: Map of the extent of gorse (marked as yellow) in the Wellington region, with insets near Wellington city (1) and Castlepoint (2).

TABLE 2: Catchments in the Wellington region with more than 200 ha of gorse. The data are ranked by proportion of catchment occupied.

\begin{tabular}{lcc}
\hline Catchment & Gorse area (ha) & Gorse Cover (\%) \\
\hline Gollans & 457 & 12.0 \\
Wainuiomata & 924 & 6.9 \\
Korokoro & 561 & 3.0 \\
Mataikona & 515 & 2.9 \\
Porirua & 206 & 2.8 \\
Okau & 232 & 2.0 \\
Hutt & 419 & 1.6 \\
Kororiki & 208 & 0.6 \\
Whareama & 243 & 0.5 \\
Ruamahanga & 488 & 0.2 \\
\hline
\end{tabular}


There are various limitations to this method for gorse mapping. At a $15 \mathrm{~m}$ pixel size the method is only sensitive to closed canopy gorse, and will not distinguish gorse at the individual bush scale. The requirement that the gorse be in flower limits the recognition of very young gorse or patches that have asynchronous flowering. The need for cloudfree imagery within the flowering period also constrains the acquisition of imagery, making it difficult for a gorse map to be made every year. However, monitoring of closed canopy gorse at regional scales could be achieved over 5 to 10 year intervals, and provide information relevant for management and policy development. It is unlikely that the techniques for mapping scrub weeds from satellite, as presented in this paper, will be applicable to weeds other than gorse, as few weeds have such a high canopy closure, profusion of flowers and long flowering season.

\section{REFERENCES}

Dymond, J.R.; North, H.; Pairman, D.; Stephens, P.; Wall, P.; Shepherd, J.D.; Dunningham, A.; Burrows, L.; Payton, I.; Bellis, S.; Burgham, S.; Lynn, I. 2001: Land Cover Database 2 Pilot Project. Landcare Research contract report LC0001/155. 37 p.

Dymond, J.R.; Shepherd, J.D. 1999: Correction of the topographic effect in remote sensing. IEEE Trans. Geosci. Remote Sens. 37(5): 2618-2620.

Shepherd, J.D.; Dymond, J.R. In press: Correcting satellite imagery for the variance of reflectance and illumination with topography. Int. J. Remote Sens. 